RESUMO: Trabalho de coleta de plantas melfferas que está sendo realizado partir de julho de 1990, na aldeia do Contão e na lazenda SB, município de Boa Vista. Através de visitações periódicas (mensais) âs localidades, a flora boservada na busca de plantas floradas visitadas por Apis mellifera. Nas plantas observadas é discemido qual o material que está sendo retirado pelas abelhas. Amostras dos vegetais são retiradas para posterior identificação e tabelamento sistemático das obsorvações realizadas.

ABSTRACT: It is collective work plants called meliferas that is has been done since july, 1990, in Contão village and in SB fam, in the district of Vista. To these places trips are done monthly and the vegetation is observed obtain flowering plants which are visited by Apis mellifera. In these vis plants it is confimed what material is obtained, drawing samples of vegetable to be identified later on.

10 andamento da pesquisa serä publicado nos pröximos Boletins.

2 Auxlliar de pesquisas do Núcleo de Zoologia do MIRR.

B. Museu Integrado Roraina, Boa Vista, 1 (1):12-16, out./nov./dez., 1990 
A apicultura racional em Roraina é una atividade recente, contando com algunas dezenas de ap witores espalhados por regioes distintas quanto ao clina, solo e vegetaç̃o.

Existe uma interacão dinämica entre clima, solo e vegetaçá, interação esta ainda pouco estudada. Para o estabelecimento da apicultura é reccesseärio sabor corso interagen esses fatores, para a escolha de areas aptas à atividade.

o comecimento da flora de una deteminaria regiz̄o pertilice omitomder relaçäo de mitua dependência entre abelhas e plantas, pois as abelhas dependem das plantas existentes como fonte de alimento e como laval de nidificaço. Por outro lado, muitas espécies vegetais drpenden das abelhas na fumcão de agentes polinizantes.

Face a escassez de dados sobme a vegetacão propicia à apicultura en Ronaima, objetivou-se a nealizaçäo de trabaihos de observaça e jdentificaçäo de plantas meliferas em duas regiöes do muicíplo ce Boa Vista, cont firalidade de se determinar o potencial apicula das referidas áreas. os dados xemidos servixão cono subsídios à formacão de um banco de gemoplasma piancas meliferas.

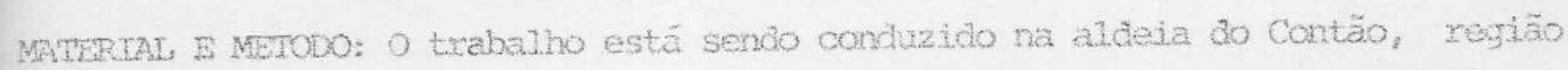
do rio Cotinge $\left(3^{\circ} 57^{\prime} \mathrm{N}\right.$ e $\left.60^{\circ} 26^{\circ} \mathrm{W}\right)$, e na fazenda SB, rio Mucataí ( $26^{\circ} \mathrm{N}$ e $60^{\circ} 50^{\prime} \mathrm{W}$ ). Arbos os locais possuem clina do tipo Avil (clime tropical can um período seco bem detinido), segundo a classificacto de Koppen. A temperatura e a precipitaçäo mêdias são respoctivemente: $27,4 \mathrm{C}$ e $1502,2 \mathrm{~mm}(4)$.

A vegetaçăo predoninante nas areas citucas, representadas pelas aldela do Contão e fazenda SB, tem na primina ds savanas do rięio surum: ma segunda, vegetaçao de transicäo entre os campos do rio Branco e a Floresta densa de baixas e majias altitudes (5).

4 EMBRAPA, 1983.

5 Atlas de Roralma, 1531 .

B. Miseu Integrado Roraima, Bos Vista, 1 (1):12 - 16, out./nov./dez., 1990 
Mensalmente, em cada local de pesquisa, as plantas em fase de floracão são abservadas para constatação de visitaça de Apis mellifora. Una vez constatada a presenca das mesmas, procede-se na verificacio do tiro de material extraído por elas, se pólen ou néctar. A seguirr, sâo coleta un tras dessas plantas, que obedecen a um processo de prensa, enumeracão e calocagão de etiqueta. Posteriox mente as amostras são levadas ao herbário do inusen paxa identificação.

Resultados abtidos no periodo de julho a novemibro, denonstramos en tabela anexa $(6)$.

AGRADECTMENTOS:

Professora Edileuza Lpoes Sette Silva, curarona do herbario do MIRR (identifica ção das plantas?

Mirts Melo (revisão final do texto).

6 Examinar tabela $1 . ; 1, \ldots$

B. Museu Integrado Roraima, Bor Vista, 1 (1) $: 12,-16$, dit./noy-/dez, 1990 


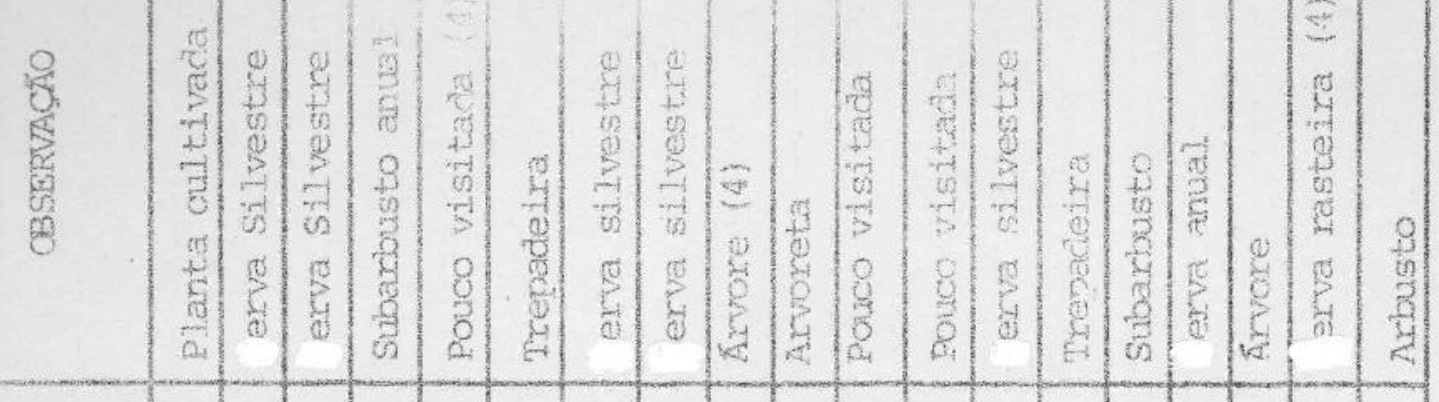

को

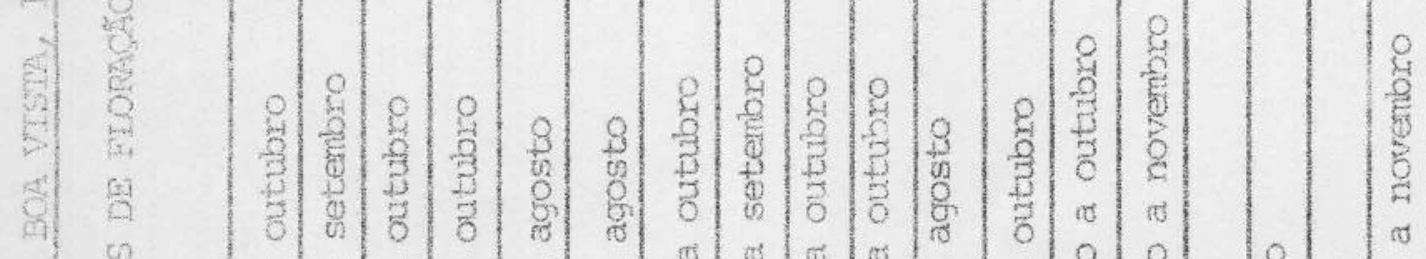

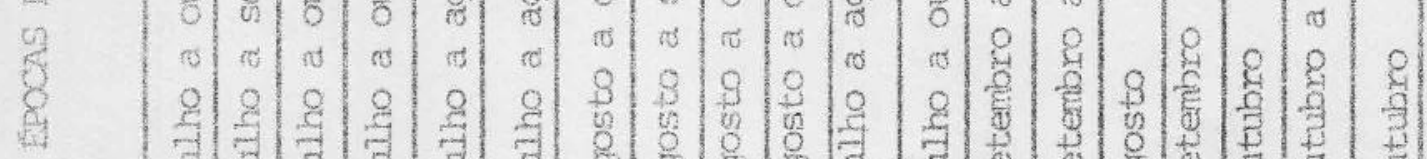

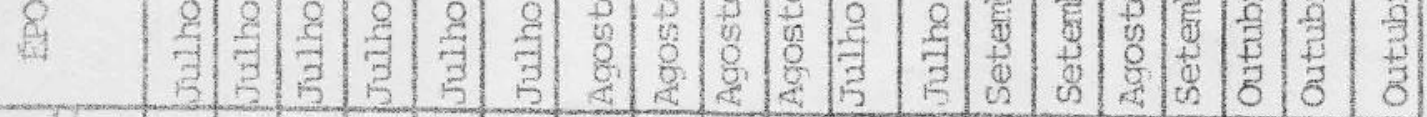

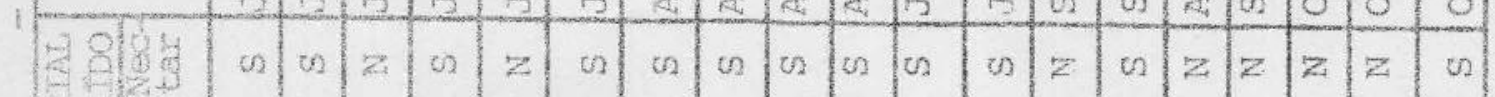

पर

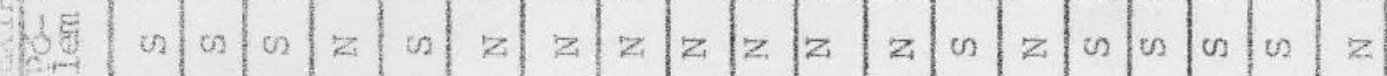

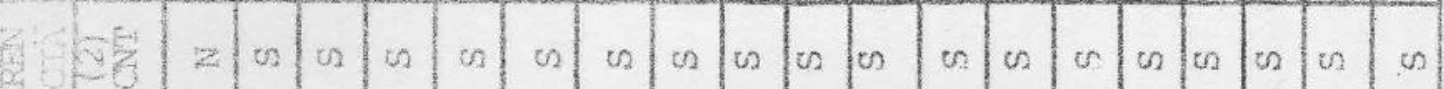

\begin{tabular}{ll|l|l|l|l|l|l|l|l|l|l|l|l|l|l|l|l|l|l|}
\hline 80 & $z$ & 0 & $\cdots$ & $z$ & $z$ & $z$ & $z$ & $z$ & $z$ & $z$ & $z$ & 0 & $z$ & $\infty$ & $\cdots$ & $\cdots$ & $z$ & 0 & $z$ \\
\hline
\end{tabular}

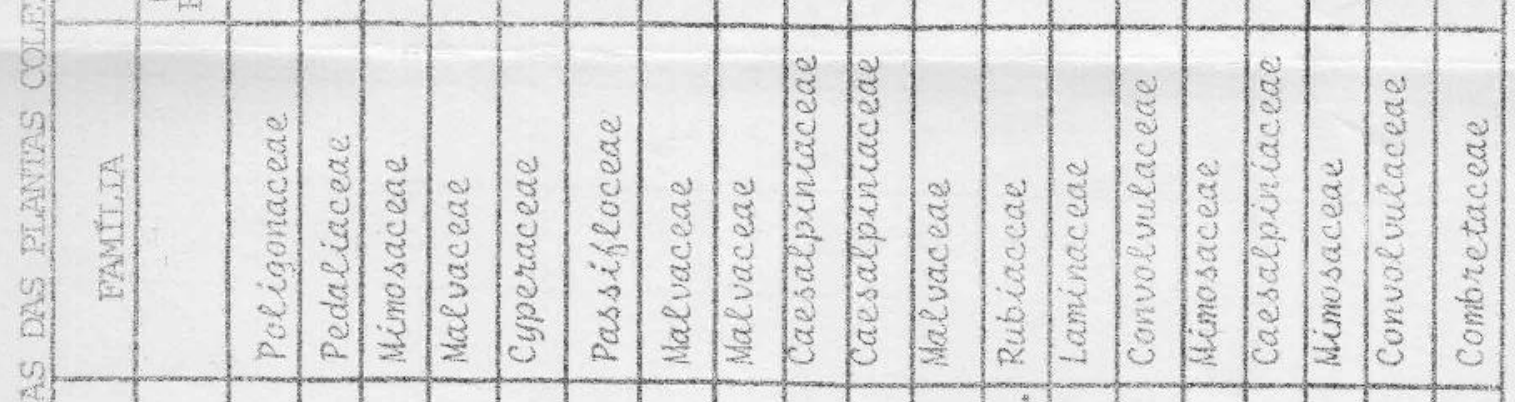

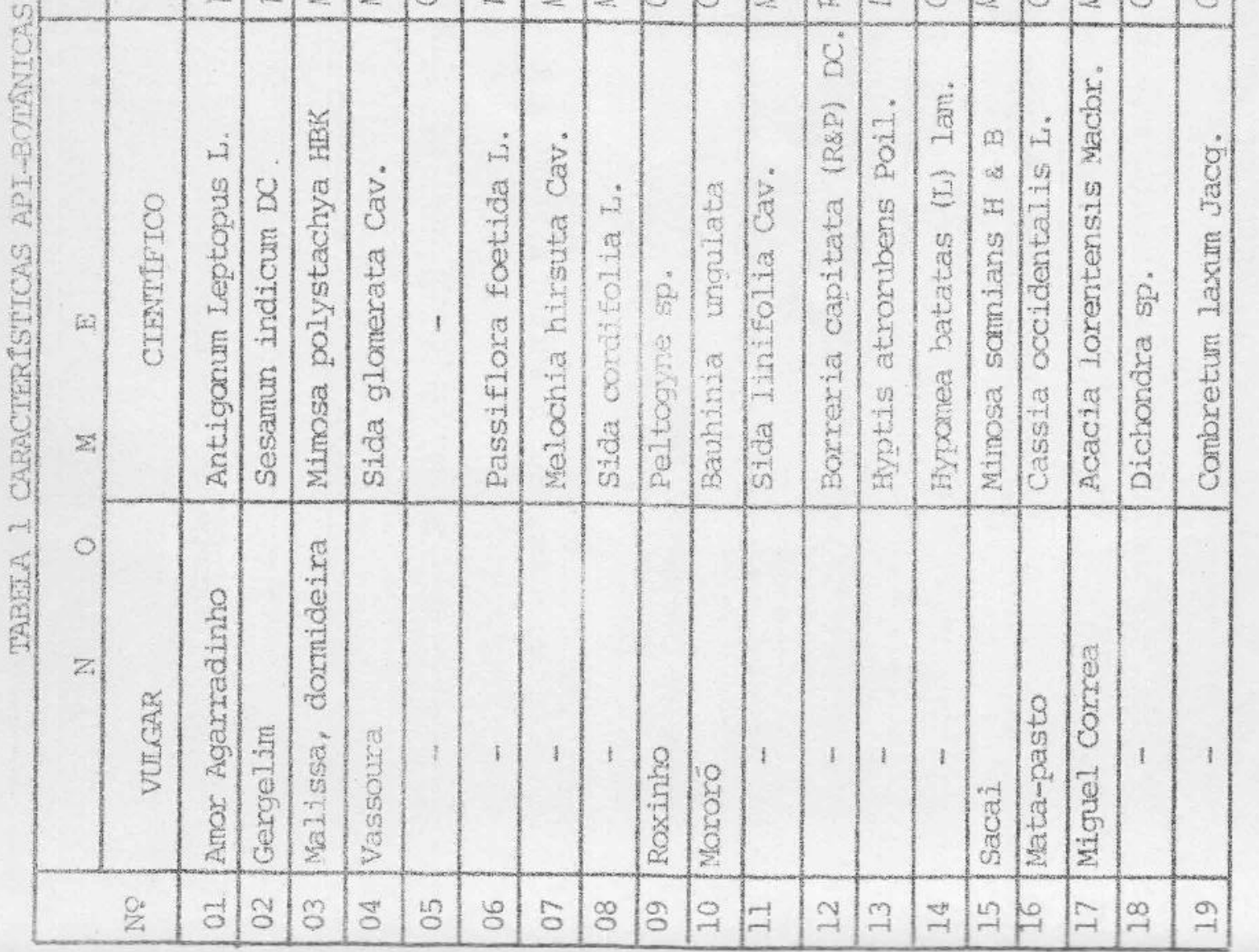




\section{PEFERENCIAS BIBLIOGRAFICAS}

MAIBACH,A - As plantas Curam, Edificação do Lar, 19 ediça revista, Itaquaquece tuba, 2985.

CAMARSO, Joz̃o Maria Franco de - Manual de Apicultura, Ed. Agronantoa Ceres, Säo paulo, 3972.

CRWE, Eva - O livro do Mel, traduçäo de Astrid Kleinart Giovamini, 20 edicâo, Nobel, São Paulo, 1987.

EMRRPA - Relatörio Recnico Anual da unidade de Execução de Pescuisa de Artoito Territorial, UEPAT de BDa. Vlsta, 1982.

Bacis - Atlas de Roraima pelo instituto de Geografiz e Estatistica, Rio de Janet. ro, 3981.

PROS\%, Plerre Jean - Apicultura, 29 edicäo espanola, Bdiciones Aundi - Prensa, Madrid, 1984.

SCHMRR, Ienhart Robert - Abelhas Bcologicas, Ed. Nobol, Sâ Paulo, 1995.

SEPUVEDA GIJ, Jean Manuel - Apicultura, Biblioteca Agricola Bedos, Barcelona, 2986.

SOJUA, Antonio Perreira - Nocöes da Gografla e Historia de Roraina, Grafica Da 1 lacio Rea1, Manaus, 1969.

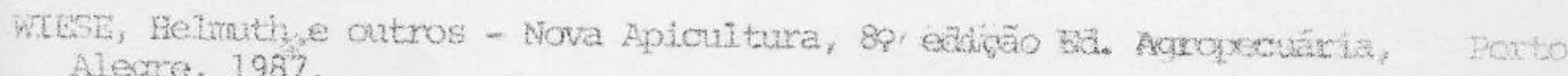
Alegres, 1987.

B. Museu Integrado Roraima, Boa Vista, 1 (1): 12-16, out./Mov./dez., 1990 